\title{
Effective Teaching - Learning Practices Adopted in Signals and Systems (SAS) Course
}

\author{
A.N. Mukunda Rao ${ }^{1}$, R. Srikantaswamy ${ }^{2}$ \\ 1,2Department of E\&C, Siddaganga Institute of Technology, Tumkur \\ 1anmukund@rediffmail.com \\ 2 rsswamy@rediffmail.com
}

\begin{abstract}
As the course Signals and Systems (SAS) is loaded with abstracts, concepts, mathematical analysis and applications, students need to remember, analyze, compare, interpret and apply the concepts to solve problems. Students find it difficult to comprehend \& understand abstract concepts. The course is pre-requisite for many engineering courses such as Control systems, Analog communication, Digital communication, Digital signal processing, Image processing, Speech processing etc., which the students study later in their higher semesters. It is therefore very essential that students be taught this course in such a way that they learn and retain the content of the course for a longer period. So teaching SAS course effectively for engineering students is a big challenge.

In this paper an analysis of the various levels of difficulties generally students face while undergoing this course is made. A systematic action plan implemented to address each of these difficulties is discussed. Finally analysis of Course Outcomes before and after implementing effective Teaching-Learning Practices is presented.
\end{abstract}

Keywords: Teaching-Learning, Signals and Systems, Tutorials, Activities, MATLAB.

\section{A.N. Mukunda Rao ${ }^{1}$}

${ }^{1}$ Department of E\&C, Siddaganga Institute of Technology, Tumkur

1anmukund@rediffmail.com

\section{Introduction}

This paper makes an attempt to identify the difficulties students normally face while learning the SAS course. These difficulties are then categorized and eventually Teaching-Learning practices are designed to address each them. Course contents include: Classifications of signals, Elementary signals, Operations on signals, LTI systems, Convolution, Difference equations, Fourier representations and applications, $\mathrm{Z}$ transforms and applications. The course outcomes are listed in Table: 2.

Course contents, topic level objectives, lecture plan, teaching learning methodology and assessment methodology are designed to meet the program outcomes.

\section{Background}

Several papers are published on improving teaching learning methodology for effective class room teaching specifically in SAS course. To achieve expected learning outcomes of the signals and system course, University of Texas at El Paso ${ }^{[1]}$ has implemented the technology-based instruction for two consecutive semesters. It is claimed that students taking the course were able to actively participate in their learning by using four technologies: Connexions, Quad base system, interactive simulations and Openstax Tutor. Students used the modules in Connexions to study at their own place and time. They were able to reinforce their knowledge in specific topics of the course from the homework feedback by using the Quad base system. The paper claims a significant improvement on the learning outcomes when technology-based instruction is used compared to the traditional instruction.

The paper, " Refined 'Chalk-and-Talk' of Lecture Content: Teaching Signals and Systems at the Griffith School of Engineering $^{[2]}$ " by Stephen So, presents that for courses such as SAS traditional way of teaching through chalk-andtalk i.e., blackboard teaching is more efficient and delivers more dividend than teaching using Power Point Presentations. 
Richard Vaz, Nicholas Arcolano WPI , 2001 ${ }^{[3]}$ discusses importance of combining outcome based learning and assessments. It emphasizes on use of Simulink tools, assignments, projects for the course.

\section{Objective}

The objective of this paper is to identify the difficulties generally encountered by the students while learning SAS and to use innovative methods to address them.

\section{Methodology}

Effective teaching of SAS would enable students to (i) learn the basics (ii) analyze the information processing challenges in real-time projects (iii) apply these concepts in other engineering courses as well.

The proposed work is classified as different phases such as (A) Identifying difficulties of students (B) Categorize the difficulties (C) Addressing the difficulties with effective Teaching-Learning Practices.

By analyzing the performances of 170 students in each year during the period 2008-11, in Continuous Internal Evaluation (CIE) and Semester End Examination Evaluation (SEE), the mistakes generally committed by the students in tests/quiz/Assignments/End exams are identified. An attempt is made to consolidate them in Table: 1

Table: 1 Analysis of Mistakes Committed by the Students over a period of 3 years (2008-2011) with a strength of 170 students in each year.

\begin{tabular}{|c|c|c|c|}
\hline $\begin{array}{l}\text { Sl. } \\
\text { No }\end{array}$ & $\begin{array}{l}\text { Mistakes committed by } \\
\text { the students }\end{array}$ & $\begin{array}{l}\% \text { ge of } \\
\text { students }\end{array}$ & $\begin{array}{l}\text { Problem } \\
\text { category }\end{array}$ \\
\hline 1 & $\begin{array}{l}\text { i) While using formulae } \\
\text { for computing Energy, } \\
\text { Power, Fourier/ Inverse } \\
\text { Fourier coefficients }\end{array}$ & 20 & $\begin{array}{l}\text { Memorizing the } \\
\text { Formula } \\
\text { Avg: } 20 \%\end{array}$ \\
\hline 2 & $\begin{array}{l}\text { i)While representing } \\
\text { signals by mathematical } \\
\text { expressions } \\
\text { ii) Performing Integration, } \\
\text { Differentiation, } \\
\text { Geometric series } \\
\text { iii) Simplification } \\
\text { iv) Performing combined } \\
\text { operations : Time shifting, } \\
\text { Time scaling, Time folded } \\
\text { signals }\end{array}$ & $\begin{array}{l}18 \\
25 \\
20 \\
25\end{array}$ & $\begin{array}{l}\text { Performing } \\
\text { mathematical } \\
\text { operations: } \\
\text { Problem-solving } \\
\text { skills. } \\
\text { Avg: } 22 \%\end{array}$ \\
\hline 3 & $\begin{array}{l}\text { i) While Sketching the } \\
\text { signals } \\
\text { ii) Taking }(\mathrm{t}-\mathrm{n}) \text { range } \\
\text { and }(\tau-\mathrm{k}) \text { range in } \\
\text { convolution operation. }\end{array}$ & $\begin{array}{l}15 \\
25\end{array}$ & $\begin{array}{l}\text { Convolution } \\
\text { Process } \\
\text { Avg: } 20 \%\end{array}$ \\
\hline 4 & $\begin{array}{l}\text { i) Confusion with } \\
\text { continuous \& discrete } \\
\text { time representations; } \\
\text { periodic \& non periodic } \\
\text { signals } \\
\text { ii) Confusion with Time } \\
\text { domain \& Frequency } \\
\text { domain operations } \\
\text { iii) Confusion with } \\
\text { Impulse response and } \\
\text { Frequency response } \\
\text { iv) Justifying stability \& }\end{array}$ & 15 & $\begin{array}{l}\text { Conceptual } \\
\text { Mistakes }\end{array}$ \\
\hline
\end{tabular}

\begin{tabular}{|l|l|l|l|}
\hline & $\begin{array}{l}\text { causality of system in } \\
\text { terms of Poles \& Zeros } \\
\text { v) Sketching of spectrum } \\
\text { of sampled signal : } \\
\text { Aliasing concept }\end{array}$ & 20 & \\
\hline 5 & $\begin{array}{l}\text { i) Applying Fourier / Z } \\
\text { transform properties to } \\
\text { solve problems }\end{array}$ & 25 & $\begin{array}{l}\text { Applying the } \\
\text { ii) Applying Z-T/ F-T to } \\
\text { find Stability, causality of } \\
\text { systems }\end{array}$ \\
\hline
\end{tabular}

"There is overlapping of students while committing different category of mistakes

\section{Effective Teaching-Learning Practices}

Considering the difficulties students generally encounter the following Teaching-Learning Practices are adopted. Ideally the Teaching Learning practices should be designed to nullify the effect of variation in faculty and student intake.

\section{A. Conducting Weekly Tutorial Classes}

Students who have secured good grade in Engineering Mathematics which is the pre-requisite for SAS course are identified to assist the faculty in conducting tutorial classes. Tutorial classes for a batch of 15 students involving these bright students of same class are conducted weekly. Oneto-one attention is possible as the strength of class is small. Problems can be discussed with students individually. Scope is there to allow the students to solve problems in their own pace. Few students hesitate to express their trivial doubts with faculty which is addressed by involving their own class mates in tutorials. In tutorial classes, each student will solve problems with the help of peer learner and faculty. This practice develops problem-solving skills among the students, encouraging them to learn from each other. Assisting their fellow class mates in turn helps them to get their concepts strengthened.

\section{B. Convolution Animation}

Since many students find performing convolution operation difficult, special attention is given to solve convolution problems through animation. This enables students to visualize the entire convolution process. Convolution Animation is developed to illustrate the convolution concepts and is uploaded on the internet which can be downloadedfromhttp://sites.google.com/site/rsswamy18/sig nals\&systems /convolution. Convolution operation for continuous time and discrete time signals are demonstrated in this animation which can be easily understood by the students.

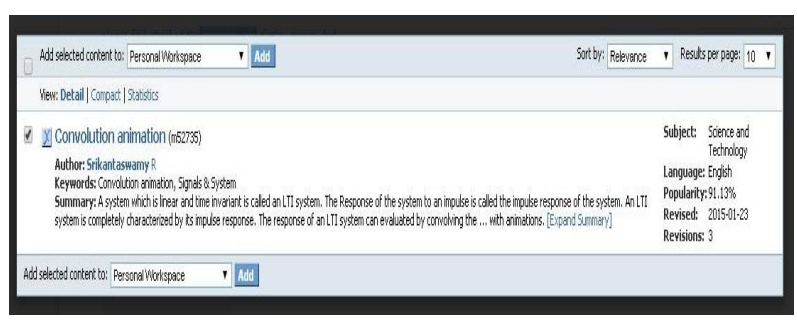


Fig:1. Openstax_cnx display screen shot

The convolution is illustrated here with couple of examples.
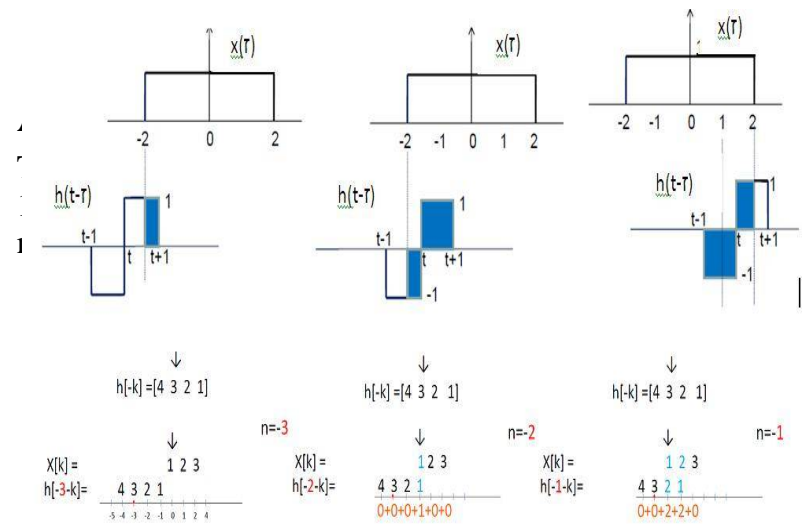

Fig. 2. Convolution examples

C. Activity Based Learning

Technical quiz competitions are organized after covering LTI systems and Fourier representations. "Pick-and-speak or sketch" is organized covering signal operations, system properties, Fourier representation formulae topics. Learner centric teaching is implemented. These activities help students to interact freely with faculty which intern enables them to get their doubts cleared. Concept retention also improves considerably.

D. Conducting Remedial Classes

To boost the morale of slow learners remedial classes are also conducted. Here students will be taught easy ways to memorize formulae. Thought provoking questions will be raised. Students are encouraged to solve a problem using different approaches.

E. Effective Utilization of Mathematical Tool

MATLAB tool is used to demonstrate the concept of representation of real valued and complex valued signals, computing energy, spectrum of signals, poles \& zeros plot, sampling theorem, impulse response, and frequency response. Some examples are shown below.

$\%$ Real Valued Exponential signal

$\mathrm{a}=0.6$;

$\mathrm{t}=[-5: 20] ; \mathrm{x}=(\mathrm{a}) .^{\wedge} \mathrm{t}$;

figure(3);

plot(t,x),xlabel('t'),ylabel('y(t)');

title('Exponential Signal');

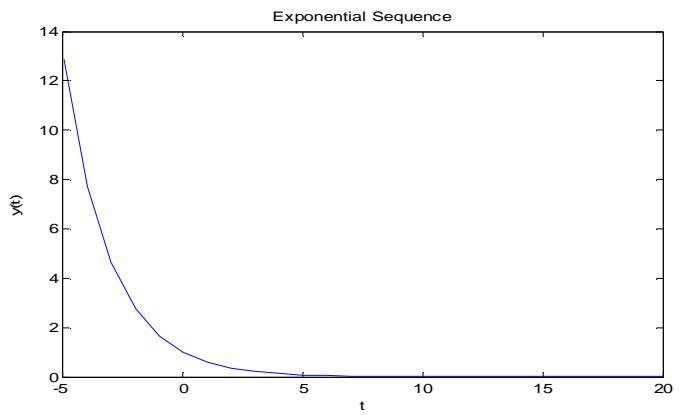

Fig.3 Exponential Signal

\%Delayed Unit Step Sequence

$\mathrm{n} 1=-20 ; \mathrm{n} 2=20 ; \mathrm{n} 0=2$;

$\mathrm{n}=\mathrm{n} 1: \mathrm{n} 2$;

step $=[(\mathrm{n}-\mathrm{n} 0)>=0]$;

figure(4);

stem(n,step),xlabel('n'),ylabel('y(n)');

title('Delayed Unit Step Sequence');

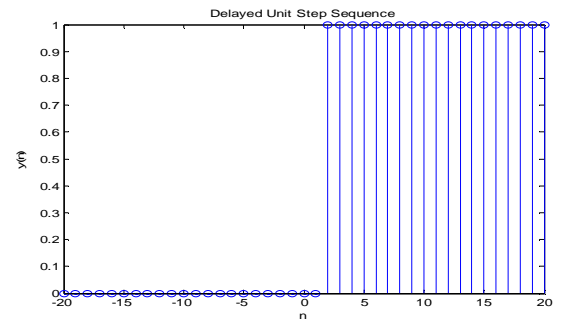

Fig.4 Delayed Unit Step Sequence

$\%$ Triangular Wave

$\mathrm{t}=0: 0.0001: 4 / 50$;

$\mathrm{x}=\operatorname{sawtooth}\left(2 * \mathrm{pi}^{*} 50 * \mathrm{t}, 0.5\right)$;

plot(t,x),xlabel('t'),ylabel('x(t)');

title('Triangular Wave');

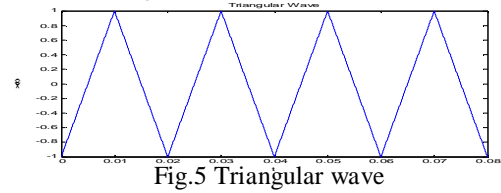

$\%$ Representing Complex Valued Signal

$\mathrm{n}=-10: 10$

$\mathrm{x}=\exp ((-0.1+(\mathrm{j} * 0.3)) * \mathrm{n})$

$\operatorname{mag}=\operatorname{abs}(\mathrm{x})$; phase $=\operatorname{angle}(\mathrm{x})$

$\mathrm{y}=\operatorname{real}(\mathrm{x}) ; \mathrm{z}=\mathrm{imag}(\mathrm{x})$

subplot(221),stem(y),title('real part of signal')

subplot(222),stem(mag),title('Mag of signal of signal') subplot(223),stem(phase),title('PHASE of signal') subplot(224), stem(z), title('imag part of signal')
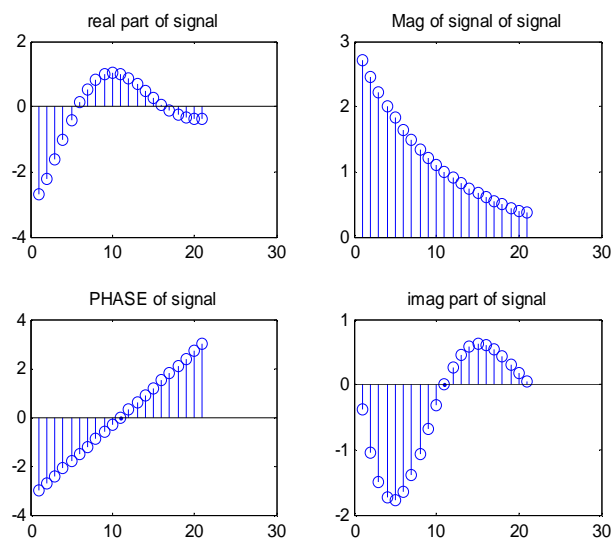
Fig:6 Representation of complex valued signal

$\%$ Energy Computation for complex signal

$\mathrm{E}=\operatorname{sum}\left(\operatorname{abs}(\mathrm{x}) .^{\wedge} 2\right) ; \mathrm{E}=40.1516$

$\%$ Representing Spectrum of a Composite Signal $\%$ signal representation

$\mathrm{fm} 1=50 ; \mathrm{fm} 2=100 ; \mathrm{fm} 3=250$;

$\mathrm{fs}=1000 ; \mathrm{t}=0.00001: 1 / \mathrm{fs}: 10 / \mathrm{fm} 1$;

$\mathrm{x}=\sin (2 * \mathrm{pi} * \mathrm{fm} 1 * \mathrm{t})+\sin \left(2 * \mathrm{pi}^{*} \mathrm{fm} 2 * \mathrm{t}\right)$

$+\sin (2 *$ pi $*$ fm $3 * \mathrm{t})$

$\mathrm{N}=$ length$(\mathrm{x})$;

$\operatorname{plot}(\mathrm{t}, \mathrm{x})$

xlabel('time in sec')

ylabel('x(t)')

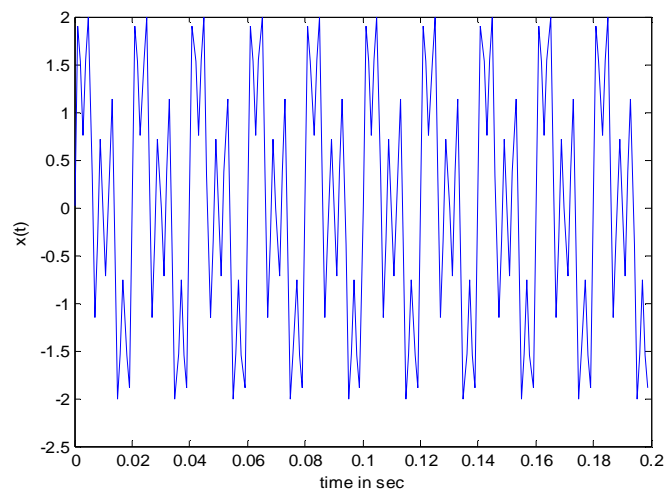

Fig.7 Composite Sinusoidal Signal

$\%$ Spectrum of signal

X_f $=\mathrm{fft}(\mathrm{x})$;

$\mathrm{l}=0: \mathrm{N}-1$;

$\mathrm{k}=(\mathrm{fs} / \mathrm{N}) * 1$;

$\operatorname{stem}\left(k, a b s\left(x \_f\right)\right)$

xlabel('frequency in $\mathrm{Hz}$ ')

title('Spectrum of Signal')

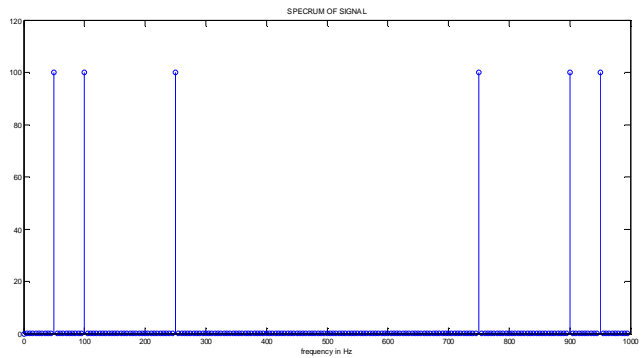

Fig: 8 Spectrum of the Composite Signal
$\%$ Poles and Zeros

$\%$ System:

$\mathrm{y}[\mathrm{n}]=\mathrm{x}[\mathrm{n}]+0.5 \mathrm{y}[\mathrm{n}-1]$

$\mathrm{a}=[1,-0.5] ; \mathrm{b}=[1]$;

$\mathrm{y}=$ zplane $(\mathrm{b}, \mathrm{a})$;

$\%$ Concept

$\mathrm{y}[\mathrm{n}]=\mathrm{x}[\mathrm{n}]+0.5 \mathrm{y}[\mathrm{n}-1]$

$H(Z)=\frac{1}{1-0.5 z^{-1}}$

$\mathrm{h}[\mathrm{n}]=(0.5)^{\mathrm{n}} \mathrm{u}[\mathrm{n}]$

Since $\mathrm{h}[\mathrm{n}]$ is Right handed side \& absolutely summable, the system is both Causal \& stable Since H(z) has pole inside unit circle, the system is both Causal \& Stable

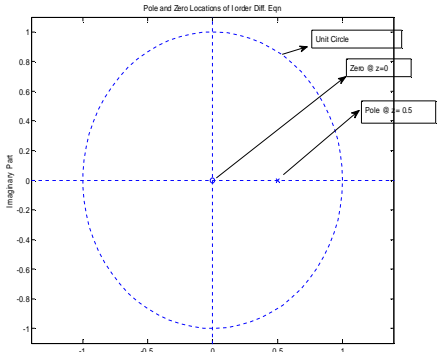

Fig: 9 Poles and ${ }^{0}$ Zeros of $^{-0.5}$ order DE

$\%$ Impulse response and Frequency response $\%$ of system

$\mathrm{y}[\mathrm{n}]=\mathrm{x}[\mathrm{n}]+0.5 \mathrm{y}[\mathrm{n}-1]$

$\mathrm{a}=[1,-0.5] ; \mathrm{b}=[1]$;

$\operatorname{impz}(\mathrm{b}, \mathrm{a}) \quad \%$ Impulse response

freqz(b,a) \% Frequency response

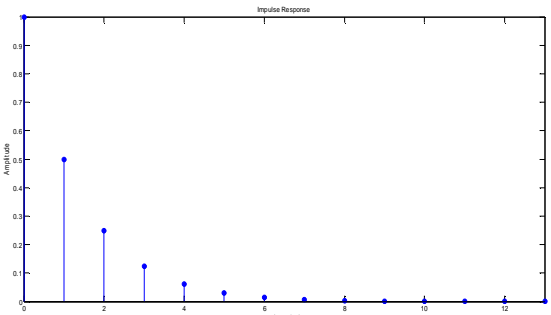

Fig:10 Impulse Response of the I order DE
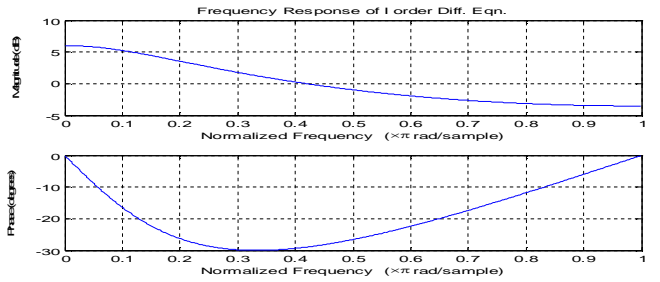

Fig 11 Frequency response of the I order DE

6. Mapping of Teaching-Learning Practices

Fig:12 shows how each of the difficulties of the students is addressed by one or more TeachingLearning Practices adopted. 


\begin{tabular}{|c|c|c|c|c|}
\hline $\begin{array}{l}\text { Course Outcomes } \\
\text { (COs) }\end{array}$ & $\begin{array}{l}\text { Before } \\
2012\end{array}$ & 2012 & 2013 & 20 \\
\hline $\begin{array}{l}\text { CO1: Evaluate different } \\
\text { types of signals. }\end{array}$ & $\mathrm{D}$ & C & B & B \\
\hline $\begin{array}{l}\mathrm{CO} 2: \text { Analyze the } \\
\text { properties of system }\end{array}$ & B & B & A & B \\
\hline $\begin{array}{l}\text { CO3: Compute the } \\
\text { response of LTI } \\
\text { system. }\end{array}$ & $\mathrm{C}$ & B & B & A \\
\hline $\begin{array}{l}\text { CO4: Analyze the } \\
\text { signals in frequency } \\
\text { domain. }\end{array}$ & $\mathrm{C}$ & C & B & B \\
\hline $\begin{array}{l}\text { CO5: Illustrate the } \\
\text { application of Fourier } \\
\text { representation. }\end{array}$ & $\mathrm{C}$ & B & B & B \\
\hline $\begin{array}{l}\text { CO6: Apply Z- } \\
\text { transforms for broader } \\
\text { characterization of } \\
\text { discrete time signals } \\
\text { and LTI systems. } \\
\text { a }\end{array}$ & B & A & A & A \\
\hline $\begin{array}{l}\text { Memorizing the } \\
\text { Formula }\end{array}$ & & & \multicolumn{2}{|c|}{$\begin{array}{c}\text { Conducting } \\
\text { Weekly Tutorial }\end{array}$} \\
\hline $\begin{array}{l}\text { Problem-solving } \\
\text { skills. }\end{array}$ & & & $\begin{array}{r}\text { Conduc } \\
\text { Remedial }\end{array}$ & \\
\hline $\begin{array}{l}\text { Convolution } \\
\text { Process }\end{array}$ & & & $\begin{array}{l}\text { Convol } \\
\text { Anima }\end{array}$ & \\
\hline $\begin{array}{l}\text { Conceptual } \\
\text { Mistakes }\end{array}$ & & & $\begin{array}{r}\text { Activity } \\
\text { learni }\end{array}$ & \\
\hline $\begin{array}{l}\text { Applying the } \\
\text { concepts }\end{array}$ & & & $\begin{array}{r}\text { Effect } \\
\text { utilizati } \\
\text { Mathemati }\end{array}$ & \\
\hline
\end{tabular}

Fig:12 Mapping of students' difficulties and Teaching-Learning Practices 7. Evidence of Success

The result of effective Teaching-Learning practices adopted is presented here. The bar chart in Fig: 13 reflect the outcome of the Teaching-Learning practices under taken during the period 2012-14. It clearly shows that percentage of students committing mistakes in different problem category has been declining since the introduction of effective Teaching Learning practices. It is also encouraging that the \#overlapping of number of students committing different category of mistakes is reduced since 2012. This has resulted in improvement of results in SAS course. Data is analysed for the same set of faculty teaching for three years.

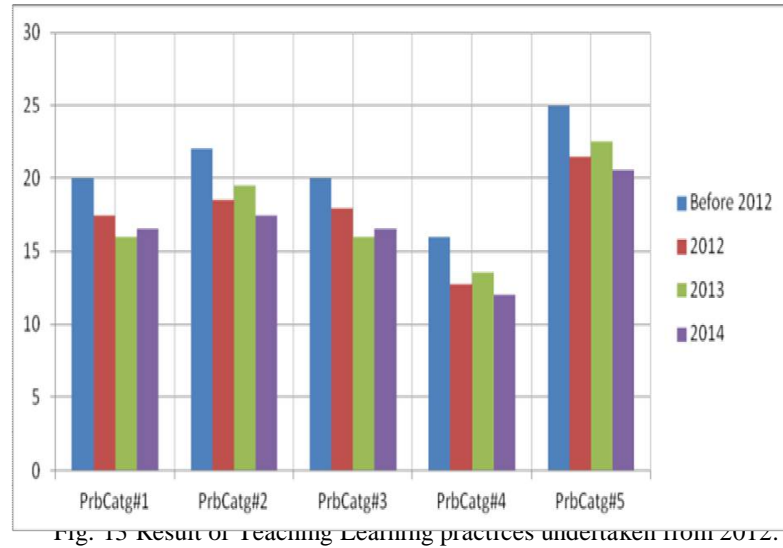

Questions from examinations, addressing each Course Outcome (CO) are considered for assessment. Marks obtained by all the students for those questions addressing each $\mathrm{CO}$ are averaged. If the percentages of the average marks are less than 45: D, 46 to 60: C, 61 to $75: \mathrm{B}$, 76 to 90: A, 91 to $100: \mathrm{S}$ grade is marked. This analysis is presented in Table: 2 .

Table: 2 Analysis of Course Outcomes before and after Implementing effective Teaching-Learning Practices

\section{Conclusion}

In this paper, a methodology to identify the common difficulties students face while learning Signals and Systems course is devised. Difficulties are identified and categorized. The average percentage of each problem category is estimated. Considering these issues, innovative Teaching Learning methodologies are designed and adopted to address these difficulties. Finally the result of the innovative Teaching Learning practices adopted is presented. There is always a scope to come up with new innovations to improve teaching and learning process to achieve good results.

\section{Reference:}

1. Dr. Berenice Verdin (2014), An Experiment to enhance Signals and Sustems learnino hy using technology based teaching Conducting ff Texas at El Paso 360 degree of Weekly Tutorial ASEE Annual, conference and Exp In June-15-18, 2014, American Society for Engineering Education, 2014, Paper ID \#10796.

2. Stephen So (2012), Refined 'Chalk-and-Talk' of Lecture Content: Teaching Signals and Systems at the Griffith School of Engineering, Griffith University, Proceedings of 
the 2012 AAEE Conference, Melbourne, Victoria, Copyright (C) Stephen So, 2012.

3. Richard Vaz, Nicholas Arcolano WPI (2001), Teaching Signals and Systems through portfolios, writing, and independent learning, Paper presented at the American Society for Engineering Education Annual Conference \& Exposition, Albuquerque, NM.

\section{Brief bio-data of author 1:}

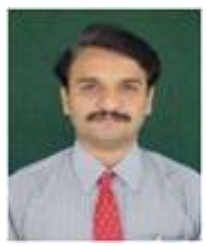

Name: A N Mukunda Rao

A N Mukunda Rao received his M.Tech degree in industrial electronics in 1994 from University of Mysore, India. $\mathrm{He}$ is working as Associate Professor in the Department of Electronics and Communication, Siddaganga Institute of Technology, Tumkur, India. He has 25 Years of teaching experience. He has taught courses Signals \& Systems, Digital Signal Processing, Arm Processors and Microcontrollers. His Area of work is Signal Processing and Embedded System.

\section{Brief bio-data of author 2:}

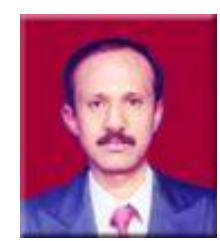

Name: Dr.R. Srikantaswamy

R. Srikantaswamy received his M.Tech degree in industrial electronics in 1995 and Ph.D. degree in electronics in 2006 from University of Mysore, India. He is working as a Professor in the Department of Electronics and Communication, Siddaganga Institute of Technology, Tumkur, India. His research interests include signal processing, neural networks and image processing. 